\title{
Carrying as Method: Listening to Bodies as Archives
}

202I, Vol. 27(I) 3-26

(C) The Author(s) 2020

(c) (i) (5)

Article reuse guidelines: sagepub.com/journals-permissions DOI: 10.1 I $77 / 1357034 \times 20946810$ journals.sagepub.com/home/bod

@SAGE

\section{Nirmal Puwar (1)}

Goldsmiths, University of London

\begin{abstract}
This article unpacks the notion of 'carrying' as an embodied set of influences that bear upon our research practices and journeys. It is widely recognised that we acquire and carry a body of books as intellectual companionship. It is not however readily acknowledged how we as researchers carry sounds, aesthetics, traumas and obsessions, which stay with us and take time to appear before us, as methodological projects within our grasp. Researchers are carriers embarked on exchanges in a double sense. Firstly, we are embodied and affected by our life trajectories. There is a temporality to our research which is entwined with the very knots of our lives. Secondly, we are carriers through the specific ways in which we activate our research materials and relationships. In this article, the two elements of carrying are underlined as being intimately related.
\end{abstract}

\section{Keywords}

archives, carrying, dementia, giddha, inter-generational, methods, song

\section{The Things We Carry}

In The Things They Carried (1990), Tim O'Brien creates a storytelling technique from being a North American Vietnam war veteran. ${ }^{1}$ Through a series of interlinked character sketches he calls attention to what soldiers carried with them. This includes material items, bodily ailments as well as a mix of emotions, all of which they carry across landscapes. Academic and artistic works have 
focused on what migrants have carried. This has included physical items, bodily marks and traces, as well as contradictory feelings; of hope, fears, dreams and nightmares (Berger and Mohr, 2010 [1975]). Researchers too carry embodied histories, obsessions, dreams and materials within specific infrastructures. Carrying could be construed as a metaphor, which offers 'theories in miniature, in utero', as the sound theorist Martin Daughtry puts it, 'in which we can think and sense the world anew' (2017: 48). This article particularly reflects on processes entailed in carrying projects inter-generationally, across time and space, involving listening to the body as an archive.

Carrying has a physical resonance, involving technologies, spaces, as well as bodies. In the essay 'The Carrier Bag Theory of Fiction' (1989), Ursula Le Guin points out how gathering is a fundamental aspect of life, one which has been overlooked in favour of tales of conquest, killing and battle. She observes how the process of making stories for her involves 'lugging this great heavy sack of stuff, my carrier bag full of wimps and klutzes...' (1989: 153). Le Guin mentions that knowledge making is 'primarily a cultural carrier bag' (1989: 154), with which we collect, hold and store. In accordance with the infrastructures available to us, our homes and offices are places of gathering research and teaching tools. In my office sits a mannequin I carry across campus, with a large label in black print on A4-sized white paper, stating:

'Carrying As Method'

Which snippets, sounds, words, stories, trauma and incidences do you carry and want to work on as research?

Write this down on the post-it or tag below and attach it to the body. 

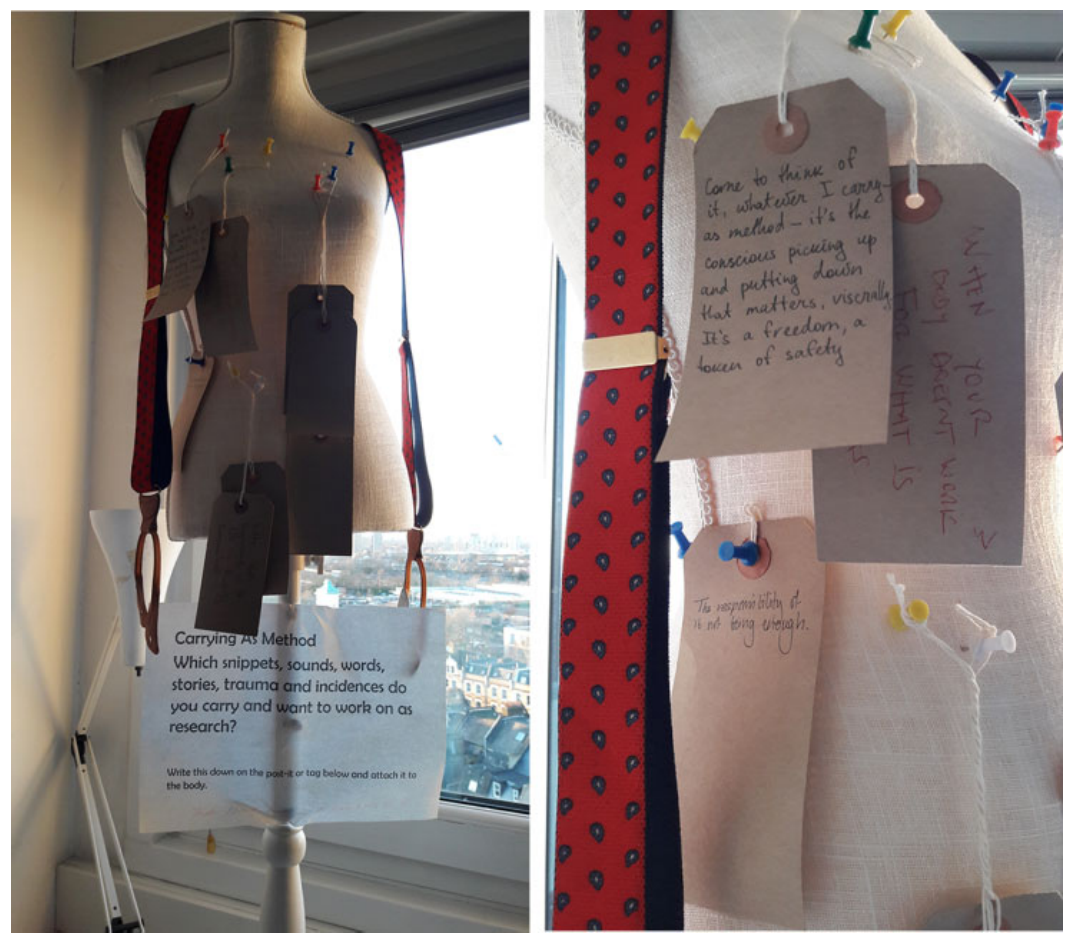

Carrying as Method, Nirmal Puwar, mobile installation at Goldsmiths

As an experiment (Marres et al., 2016), I initially operationalised the piece to function as an impromptu classroom device, to encourage students to reflect on an issue or project they have carried for some time and might want to develop further. I contextualise the pedagogic exercise by speaking to how we all carry incidents and experiences from the past with us. We are embodied beings as knowledge makers. Encounters, connections and relationships influence and impact on the research we undertake. The exercise provides an opportunity to pay attention to flashes, snippets, sounds, words, stories, traumas, scenes and incidences which keep turning up. These may actually keep returning and circling us, without knowing exactly how to hold them and give them intellectual and creative attention. Academic projects can be entangled with life events, though the unfurling of this entanglement into a 'project' is not a linear development. Ideas emerge in fits, stops and starts, taking shape, methodologically, like a cat's cradle (Haraway, 1994, 2008). Living along lines and knots; untangling and re-knotting within new 
patterns of knowledge making (Strathern, 2004). The exercise facilitates the possibility of learning to recognise a topic which one has been carrying for some time. Participants are invited to write on a Post-it or tag, which they then either pin or stick on the mannequin or on a white board, before reading and discussing the posts exhibited. The writing and exhibiting facilitate a mode of participation and exchange. The mannequin becomes a holding space, a collective gathering and a probe for engaging with the often unacknowledged intimate link between ideas and lives. Never does the pedagogic encounter assume that we will consciously pin down everything that has thus far been beyond our tangible grasp. The exercise tugs on threads of memory, as a mini exercise in memory work (Portelli, 1997).

The material circulation of the mannequin has engendered different affective registers, depending on its assemblage. The mannequin took on a slightly altered life, as a 'material participant' (Marres, 2014), when I located it within the conference Archives Matter: Queer, Feminist and De-colonial Encounters (2016), organised by Chandra Frank for the Centre for Feminist Research at Goldsmiths. On this occasion, as an impromptu material insertion, the mannequin stood on a table, within a lobby area, in a place where there were other multi-media art works also on display. People passed by or stopped at the mannequin and pinned their thoughts on what they were carrying on to the body. Some comments were general, such as 'the violence of colonialism'. Others referred to personal events. The comments from the diverse environments the mannequin has been placed in together constitute a paper archive. They become archival scraps of paper bearing the traces of their sites and situations of circulation. Having not intended to collect the statements in any systematic way, I have only held on to a small sample. The main point of the exercise has always been on the process it affords for reflecting on what we carry, and how as a device it can help us to identify and craft what may have hitherto been fleeting attentions into a prolonged research and/or creative project.

Over the years, I have taken along my accomplice, the mannequin, to a number of classes. The task and the thinking it engenders often stays with students across the course of the degree, with many of them referring to carrying as a method in assignments. Reflecting on the process of working with and on the mannequin, for an intensive 
Feminist Methods Workshop, a postgraduate student, who had carried stories of violence against women, from her friends and family, and had wanted to work on the issue for some time, noted that the very material and bodily act of pinning the tag she had written on to the mannequin felt like an act of violence too. Research can indeed be an act of epistemic violence and extraction, which is one of the reasons we sit on projects or never take them on.

To place myself in the exercise, early on I share an example of a topic I have carried for years before making it into a 'project'. I mention songs, Punjabi boliyan (couplets) and giddha (female dance) carried as performative habitual memory, rather than scriptural memory, by South Asian women transnationally across diasporas. As a second-generation British-born South Asian daughter, I have carried the songs inter-generationally, as an embodied sense of knowledge, of the ways in which they have been performatively enacted, as impromptu modes of gathering by my mother's generation, in front rooms, parks and community halls in the post-war period. These scenes provide flashes to the imagination of post-war histories, far removed from how transnational subaltern private-public scenes have been imagined in feminist literatures (Fraser, 2007). I articulate to the students the notion of carrying in a double sense: of how I have been the inter-generational researcher-daughter carrier, of what has been performatively carried transnationally as a living diasporic archive (Hall, 1999). Thus students acquire a sense of how one can for some time be in the middle of beginning a project.

\section{Inter-generational Carrying in the Archives}

Inter-generational modes of carrying can take the form of searches in paper archives, as well as other types of archives, found in the form of ephemera, music, cooking, objects, landscapes, buildings, feelings and bodies. Research endeavours can constitute an often subconscious haunting search for inter-generational connection. Connections are built in the modes of transmission we seek. This article specifically emerges from within feminist studies on being a body in the archives, while searching for bodies in the archive. Scholars' bodies are centrally recognised as archives.

Like the scraps on the mannequin, the texts, images and recordings in an archive are fragments of memory which can tug on the bodies 
of scholars in the archive. Searches in archives are emotionally and politically entwined. This section reflects on how inter-generational carrying occurs through the relationships we seek out and build in archives, with archives involving paper, things, bodies, sounds, feelings and above all relationalities. The risks of epistemic violence within research or artistic practice have been underlined by a large body of scholarship in postcolonial studies and in feminist scholarship. Indeed, often archives matter because of the symbolic violence entailed within the statements, typologies and categorisations contained within them. Postcolonial feminists have, for example, foregrounded how the figure of sati (a widow immolated on the funeral pyre of her husband) is produced and written into colonial accounts of a very specific and regional Hindu ritual in India. Lata Mani $(1992,1998)$ has poignantly identified how witness accounts, scribed by British colonial male administrators, tell us more about the projections of colonial masculinities and the modes of governance, than of the widow herself. In observations of colonial archives, postcolonial feminists have highlighted affective properties in the archives. Sensuality, tropes of chivalry and an imperial White masculine 'rescue paradigm' sit within the paper archives (Rajan, 1993; Spivak, 1988). Engagements with paper archives so often involve identifying the epistemic violence while also reading in between the archives and against the grain of the ordering of the archive (Stoler, 2010). Interestingly, even as postcolonial feminists have richly discussed how the figure of sati exists in between the papers, as an inscription of an imperial masculine mode of documentation, we still seek her out in between these official accounts. When rummaging in the colonial archives we search for the subaltern figure. In pursuance, we follow traces as we are pulled in by the search for this figure.

There is a relation between bodies and archives. We carry both a relation to the dead bodies we go in search of as well as carrying our own bodies, as researchers in and out of the archives. The bodies of researchers are themselves archives of histories and labour. Affective responses to being in the archives are as much a part of scholarship as is the analysis of the affective registers within the very collection of the documents which end up in archives. Feelings ensue in the constitution of archives, as well as in the searches we carry out in between archival materials. The fragments scholars retrieve can embed themselves in their bodies, relating with their own archive 
of feelings and body memory. Or, as Carole Steedman (2001) puts it, in between the confusion of the lost and found we still go looking for certain bodies in the archive. Having met the figure of the child 'watercress seller' through the narratives of Henry Mayhew, Steedman (1986) developed an obsessive search. She found herself repeatedly returning to the watercress seller (2000). Within the process, Steedman analyses that she was imaginatively driven by a desire to claim the watercress seller from the past, as the child's fantasy mother. Reflecting on how she was simultaneously also in search of her own childhood and mother relationship, which was different from the one she projects on to the watercress child, Steedman mentions how 'the Little Watercress Girl is what I want: the past, which is lost and which I cannot have; my own childhood. She is my fantasy child' (2000: 24). In Landscape for a Good Woman (1986), Steedman notes how she found herself weeping in the archives, when hearing of the difficult labouring childhood experiences of maternal generations in her family, who left home at a young age to work and live in distant cities. Their conditions of labour and life were brought closer to Steedman in between scattered fragments of the archive. She was affectively arrested in the inter-generational daughter-mother-grandmother body memory in the archives. In Wayward Lives (2019), Saidiya Hartman's psychic inter-generational investments draw her to the scraps in the archive that offer clues to the radical and creative new intimacies forged by young Black women in segregated cities of the northern United States in the early part of the 20th century. Hartman institutes what she calls a 'critical fabulation', speculatively telling imaginative stories from omissions in the archive (2008).

In An Archive of Feelings (2003), Ann Cvetkovich in her analysis of sites of trauma and grief, as radical spaces of possibility, raises the question of what constitutes an archive and where you might find it when you go looking, especially when there are no official records. She makes the important point of highlighting how archives don't only exist in traditional storage systems or official paper archives. Cvetkovich states that her 'focus on trauma serves as a point of entry into a vast archive of feelings, the many forms of love, rage, intimacy, grief, shame, and more that are part of the vibrancy of queer cultures' (2003: 7). These feelings are mobilised, often in vibrant and productive ways, within movements and cultures of care with lesbian sexuality, AIDS activism, sexual violence and migration. There is, in this mixed 
composition for instance, an 'Urgency of illness and death in the mix of activism. Friendship and art in ACT UP' (2003: 176).

Archives of feelings not only exist in narratives, they are also to be found in DIY and activist processes of support, which don't pathologise as therapeutic systems of ordering can. Cvetkovich grasps archives of activism which are alive. Music, song, ephemera, objects, placards, novels and films enable the affects of trauma to serve as the basis of public cultures of mobilisation, intimacy and support, which in turn constitute affective archives. Thus the archive of feelings exists in DIY modes of record-keeping and inscription, most often found within 'fragile' and independent media. Archives become emergent and distributed across technologies, spaces, objects and bodies. Cvetkovich's own project is very much involved in collaboratively making an archive. Noting the ensuing 'epistemological and political challenges of the absent archive' (Cvetkovich and Carland, 2013: 76), Cvetkovich points out that ephemeral traces can make for an 'unusual archive' (2003: 7).

Stretching not only what an archive is, as well as what it becomes inter-generationally and transnationally, in the book Haunting the Korean Diaspora (2008), the unusual and everyday archive for Grace M Cho consists of the female body as an archive of memory, one which is haunted across time and scattered across spaces. Records often explicitly erased from paper are evidenced, Cho argues, in 'body memory' (2008: 63). Cho works with her own dreams and her mother's hallucinations to delineate how the inter-generational loss and trauma of sexual labour under Japanese colonialism, American militarisation, as well as migration, is lived inter-generationally, as it is distributed and embodied differently across the bodies of grandmother-mother-daughter. Through an auto-ethnographic project Cho responds to and makes sense of her relation to a cultural inheritance of two traumas - Japanese colonial conscription of girls into sexual slavery for the military, as well as the civilian massacres by the US military during the Korean war, followed through to the yanggongju, or Korean sex worker, who subsequently marries a US soldier and migrates. The histories of militarised violence perpetrated by the United States in Korea are repressed. Still this memory of violence is carried in the 'bodily matter of the survivors' as well as the periodic 'ghost flames' which erupt in the interactions of bones, soil and weather in the very spaces of obliteration (2008: 19). Cho 
notes that the figure of the yanggongju 'carries the weight of this history' of US destruction (2008: 20). But she remains an elusive figure, as 'the yanggongju slides from hypervisibility back into the shadows again' (2008: 22). The US narrative of peace maker, international cooperation and interracial romance, shifted the yanggongju from being a 'yankee whore' to a GI bride and member of kin. In the process, the intimacies of violence are, unsuccessfully, erased. The price of failed erasure and assimilation produces an unusually high rate of mental illness. Cho's project works from within illness and 'irrational perception', as daughter-researcher (2008: 23).

Cho of course is not alone in her search for inter-generational memory via the body. Second-generation Korean diasporic scholars and artists have been living and working with 'han' (unresolved grief and rage), which has been carried and transmitted across generations, reworking their inter-generational haunting by a female lineage of transnational migration, occupation and sexual relations. Together their 'recursive longings' (2008: 96) have been arrested by a 'meandering search for the elusive female figure that haunts the Korean diaspora' (2008: 90). Extending Cvetkovich (2003), we can say that this generation share an archive of feelings, of shame, obliqueness and injustice, leading them to pick up, re-trace and design etchings of what they have been living with, hearing as well as not hearing for many years. The unspoken stories passed down from flesh to flesh (2008: 121), as well as the hallucinatory voices which speak to Cho's mother, constitute an 'assemblage of the body memory of transgenerational haunting' (2008: 174). Cho underlines the 'gap between the body and the voice', which requires us to be open to 'new forms of perception'. She urges that an awareness of other forms of body sensate memory 'is particularly relevant when the traumatized subject cannot remember and recount her history in narrative form' (2008: 189). Towards the latter years of her mother's life Cho started to work on food, memory and recipes her mother shared when Cho cared and cooked for her.

\section{Temporality and Research}

Cho delves into the difficulty of pinpointing the beginnings of a project, as well as the time lapse which often prevails in topics one 
has carried, especially difficult ones, entangled with mental illness, erasure and transnational diasporic dislocations. She notes:

somewhere during the early 1990s when I was coming of age and feeling suffocated by the knot of the emotional residue that Koreans call han, winding itself up and around the strange things my mother heard, a legacy of family secrets, and the seeming contradiction between hearing too much and not saying enough. Maybe my search began there, but it did not become apparent until much later. (2008: 191)

Social and political events impact on our research directions, as do the research priorities of funding bodies. Biographical features of a researcher's life can also be central to the timing and rhythm, from when we begin a research topic to the pace at which it proceeds. Cho (2008) mentions how her interest was stretched across time, over many years.

Yasmin Gunaratnam (2013) started her research on end-of-life care after her mother died of cancer, which was soon after her father had passed away. She became compelled to process and understand end-of-life care, conducting a doctorate in the field and several related projects. Biographical aspects impact also on the time difference between when research is carried out on a topic and when it is published. Some 20 years after Gunaratnam had started the project she published the book Death and the Migrant (2013). It was difficult for her to write the book any quicker because the nature of end-of-life stories were such that they warranted ' ... the taking of time to live with stories and their affects' (2013: 20). Across the 20-year duration she was both processing her own losses (two parents in the space of a year) as well as what she had been witnessing in the end-of-life stories in her research with a hospice. Both aspects required a slow scholarship and long duration of staying with the problem. It is not often recognised that the speed of writing a project is tied up with phenomenal life events. Of course the machinic tie-in between institutional cycles of output linked to grants, research exercises and promotion mechanisms makes slow scholarship extremely difficult (Gunaratnam, 2012; Mountz et al., 2015). The rhythm of writing can also be joined up with the losses and illnesses of those close to us. Mariam Motamedi Fraser wrote the book Word (2015) as her close friend Collete was living and dying from upper motor neurone disease and losing her capacity to speak. During the course of writing 
Word, Collete lost her speech. As Motamedi Fraser was using the keyboard to finish her book, Collete was typing into a 'speechmachine' to communicate (2015: xii). Collete hoped to see the book in its finished form before the illness engulfed her. Motamedi Fraser was more than aware of this imperative to finish 'just-in-time'. While others, understandably, could not have been able to bear the weight of this responsibility, she managed to persist and Collete was able to attend the book launch.

Feminists have often engaged intimate traumas as productive points of exploration and intervention. Several studies on the body and the archive are connected within trauma (as discussed above). Cho (2008) stays with inter-generational transnational diasporic traumas of sex labour and militarisation, many of which are not known. She has been connecting threads and sitting with knots between daughter-mother-grandmother, through the materiality of art, writing, film, paper archives, cooking practices, dream work and hallucinations. The very notion of trauma and knowledge is also often turned around by feminist work. For instance, in Archive of Feelings (2003), Cvetkovich shifts queer trauma studies away from a pathologisation of the phenomena towards a recognition of the connections and intimacies (personal, creative and political) which have formed the basis of a public culture, acknowledging how the accumulation of pain is channelled towards an activism which produces an archive with alternative therapeutic and affective dimensions. There are times when projects don't begin with a trauma but the life of the project becomes lodged in a trauma due to life events around us. Motamedi Fraser began theorising Word a considerable time before her close friend Collete was diagnosed with motor neurone disease. As she wrote Word (2015), the physical and emotional reality of communicating with diminishing spoken words became etched into the very journey of the book.

A compelling personal situation led me to work on a creative project which I had, like Cho, harboured for over a decade. As a sociologist, having worked on post-war film social scenes (Puwar, 2007), I knew there were further diasporic, transnational, gendered vernacular everyday art forms and social scenes which required close-up attention (Brah, 1996). I had imagined spending time on songs and dance performances women had carried transnationally, from India across the diaspora, which were reinvented and 
performed in all-female impromptu informal gatherings in the United Kingdom. The words I had heard as a child, often in informal gatherings in British front rooms when women came together, referenced places, emotions and events. Boliyan (speech) and giddha (dance) have a to-and-fro element to the structure of the phrases and refrains used. They are typically performed in a group, of women sitting or standing together in the formation of a circle or semicircle. Usually one woman introduces a boli and the rest of the women join in on the chorus, with the adjoining sound and motions from clapping. In my case, a long-time interest in giddha and boliyan turned into a necessity, due to my personal connection/disconnection with my own mother's dementia (Parmar and Puwar, 2019). Although traumas are part of some of the songs women have sung together and carried, pain is just one emotional aspect of a vast range of repertoire. My interest in giddha and boliyan was not initially sparked from a trauma. It was the comedic, humorous passage of rites, play acting and gender crossing, spanning the whole gamut of lyrics and dance performances, which have caught my imagination. From the outset it was the vivacious pulsating use of lyrics and bodies in the informal gatherings which drew me to the social scenes of giddha.

The informal gatherings spoke of unrealised aspects: of transnational public-private female spheres; of a post-war Britain not recognised in the proliferating histories of this period; of the performative playfulness of gender and sexualities; of female aural forms of remembrance and reinvention carried across the seas; of a musical archive beyond what is passed on through masculinist dominated music industries; as well as of the gaps in informal modes of intergenerational cultural inheritance across female kith and kin. The importance of working on giddha acquired urgency in 2016 as my mother's dementia advanced, with her speech, sight and recognition becoming impaired. This was a project which I had until then, fired up, in stops and starts. While my interest in boliyan and giddha was not forged through trauma, my relationship to the songs and formations became enfolded into incremental traumatic developments over a period of time. Thus it became an imperative to work with giddha as a potential resource of connection as my mother's cognitive ability and speech were becoming impaired. 


\section{Body Memory}

The dance scholar Andre Lepecki (2010) has noted how the body is an archive of dance techniques, movements, habits, gestures and tics. Repertoires can be re-enacted (Stalpaert, 2011). In How Societies Remember (1989), Paul Connerton distinguishes between two types of official cultural transmission, a scriptural inscription and performative rituals. While the former is based on paper, scribes, record-keeping and the written form, the latter involves ritualistic enactments of bodies in sites and places, shaped by sequences and choreographies of objects, bodies and spaces. With some social occasions being strictly state-sanctified and other forms having a looser arrangement of bodies and settings. Body memory, as recognised by Emile Durkheim, is effervescent ritual (see Narvaez, 2006). Pierre Bourdieu (1990) refers to doxa as deep-seated structures of embodied dispositions. These are learned not through thinking alone but through bodily know-how. We acquire a practical sense through bodily effort. The body thus has a memory through doing. The body has an archive incorporated into a habitus. If we take habitus to be 'history incarnate bodies' (1990: 190), this is a habituated bodily archive, sedimented from past trajectories which we activate, often unconsciously, through know-how. Knowledge comes into being when the body is put into motion. Michel De Certeau et al. (1998) mention that Bourdieu has not focused on doing enough, or the feminine. In The Practice of Everyday Life (Vol. 2), they pay attention to cooking practices, as everyday gestures full of body memory, rhythm and motion:

Whether it is done with a tool (chopping an onion with a small knife) or with the bare hand (kneading bread dough), the technical gesture calls for an entire mobilization of the body, translated by the moving of the hand, of the arm, sometimes of the entire body swinging in cadence to the rhythm of successive efforts demanded by the task at hand. (1998: 202)

Diana Taylor (2003), in her analysis of performance, has mentioned that cultural memory is an archive that is an active 'canon', which is performative and continually being rebuilt and reformed. A repertoire of music and ways of singing are socially habituated. Musical as well as other cultural dispositions are socially inherited and passed on through formal and informal spaces of learning. 
The cultural transmission of the 'canon', of boliyan and giddha in the diasporic context, is certainly reformed. Boliyan and giddha are located within an assemblage which has also been reinvented in new informal diasporic settings (Purewal and Kalra, 2010). With new words and scenarios, such as Margaret Thatcher from the United Kingdom, being introduced, giddha and boliyan have been passed on in situ, in the very dramaturgy of performance. Borrowing from Motamedi Fraser (2015), with giddha we can appreciate how words are multisensory, living within complex assemblages. For some songs/performances in situ dressing up with risqué poses is involved. Depending on the boli, this can consist of clapping, stamping the feet, or a lead singer gesturing with arms, fingers and hips. Within the more animated giddha gatherings, there is a humorous play with a male role via objects, often signifying the phallus. As a performance this sits somewhere between masquerade, drag and pantomime. These scenes and songs can be 'bawdy, contain sexual innuendo and swear words, offering a more subversive slant on life and transgressing normative social behaviours for the women' (David, 2015: 156).

\section{Dementia I}

I am Looking for Her.

She is Looking for Me.

If we consider the body as an archive, it is an accumulation and coagulation of physiological, social and ecological trajectories. Song and music present radical possibilities for cognitive impairment and especially dementia. This is also the case with food, with the taste and smell of 'home' foods being a source of comfort and communication in later life (Lee, 2000), as activated in the lived histories of disease management (Ferzacca, 2004). In the field of dementia studies, it is often noted that the onset of dementia is akin to continuous bereavement. As neurological impairment progresses, the person transforms and starts to fade away. Over time, a person living with dementia can stop recognising who their partner, children and close ones are. Dementia however is not a zero-sum game. This neurologically diverse phenomenon exists on an uneven plane, with flashes of recognition. The weight of resignation to social death has been 
questioned by patient interest groups as well as pioneering professionals in the field, who alert us to the creative question: how can you live well with dementia (Waller and Beeharee, 2002)? The question has implications for how we enable participation and connection. Epistemologically this involves listening differently. Ellis and Astell (2004, 2008, 2011) found that even in advanced dementia people maintained the urge to communicate, making it necessary to discover the full range of communicative repertoire so that it can be reflected back to develop a multisensory shared language, which is non-verbal or sub-vocal (Caldwell, 2005; Caldwell and Horwood, 2007). The Hearing Voices Network draws attention to the kinaesthetic unconscious modes of hearing embodied in sensations, rhythms and movements (see Blackman, 2010).

It is now recognised that music memory often remains even in the advanced stages of dementia. While episodic memory deteriorates, procedural memory remains. Music is stored in procedural memory, associated with repetitive and muscle memory, leaving us with an opening for communicating with those assigned otherwise to being blank (Aldridge, 2000, 2005). There is a rich structure of associations with musical memories (Omar et al., 2010). Music can arouse surrogate emotions hard wired in the neural apparatus of the brain (Clark and Warren, 2015). The bonds formed with familiar songs and lyrics from a young age establish a recognition which is maintained even in advanced dementia. Hearing personally salient music is known to facilitate involuntary autobiographical memory. Thus, as a practice, music offers scope for affirmation and relational connections. A lucid 'awakening' has been affirmed in response to autobiographically salient songs (Hayden, 2007). Occasionally, this may be like a large firework explosion of colour and music. More often, there will be sparks and small bursts of engagement with song and music.

\section{Playing the List}

Internationally, a number of initiatives support singing and music as a way of connecting and enhancing the lives of people living with dementia. Research on music and dementia, led both by academic and non-academic partners, has developed an array of methods for tapping into musical biographies. One popular creative method has 
involved devising bespoke playlists, which operate as an autobiographical auditory history of songs and music specific to the person in mind. In the United Kingdom, a report from the Commission on Dementia and Music (2018) has underlined the importance of music to caring and living well with dementia. Given the context of austerity we have to be careful this does not translate into pressing a button for pre-recorded music. Linda Maguire et al. (2014) has stated that it is important to sing with and to use gestures rather than simply play background music. Listening to recorded music on a headphone is very different from singing with others in a group.

Within the global South Asian music industry, boliyan are reformulated in a masculinised format and giddha has become an ossified heritage product. There is a participative performative ecology to giddha and boliyan. If contemporary fusions on a playlist were played to my mother, she would have struggled to connect this music with her own repertoire of giddha and boliyan. Besides, the participative element, of the specific body movements in tandem with singing, would have been missing. For the generation of women who migrated in the post-war period from South Asia and are now in the 70-90 age range, they would have been accustomed to boliyan and giddha as a group activity, practised with friends and families, as an activity for social occasions or impromptu gatherings.

\section{Singing Back}

Gunaratnam has insightfully described my attempts to work with giddha as a process of 'singing back' to the space and time of informal giddha gatherings (2013: 7). Giddha is importantly 'entwining with the prosthetics of disability and disease' (2013: 7). At an everyday level, due to what was being lost, singing became a way of connecting with my mother. Her lucidity arrived in bursts, flickering on and off, with sarcasm and grace. Often names and refrains were repeated. I reinstituted songs and performances I had intergenerationally carried. Our orchestration of song, gesture and sound became a call-and-response, push-and-pull process of exchange, enabling us to reach for each other, to come together and to be touched by the textures of singing and the associated actions. In the exchange of boliyan and giddha our lives were mutually enhanced. Even though there was much that remained in my mother's 
procedural memory, access to the songs was not easily within her independent grasp. She was largely reliant on a second person to prompt and lead her into song and movement. Of her own accord she could at times break into a beat with her hands. Mostly she required another person to spark up her store of boliyan. Seeking to prompt a 'therapeutic atmosphere' (Sonntag, 2016), I often selected boliyan with celebratory or comedic banter and gesture. Foot tapping, clapping and circling her with songs would incite a return of words and emotions in my mother. A to-and-fro duo between mother and daughter orchestrated a micro version of the group gatherings of giddha. Nevertheless, we produced a rich contact zone. If further members participated in our home setting, the banter would expand and the merriment would heighten, especially if props were called upon. Broomsticks could stand in as walking sticks or scarves and towels become makeshift turbans to mimic elder men. The use of musical instruments at hand or sounds made from utensils could intensify the arrangement.

Cvetkovich (2003) has noted that she was not only analysing an archive during her research, she was also producing an archive of songs, ephemera, films, literature, photography and audio recordings. Importantly, Cvetkovich (2003) aimed to go further than what she referred to as the 'solemnity of feminist work', wanting 'something more than self-righteous anger or hushed tones of sympathy or respectful silence... [something] ... raw, confrontational, and even sexy' (p. 4). In boliyan and giddha, one can witness emotions across the whole spectrum, of the painful and solemn, sitting alongside the raw and sexy. Noting the affective qualities of lyrics and movements, the repertoire makes it possible to extract a performative playlist rather than just a song playlist.

As my mother moved into the weeks of sleep, which can occur before death, we as a family spoke and sang key refrains to her from the songs she had responded to in the recent past. Since her passing on 16 April (my birthday) in 2019, my relationship to the archive of songs and giddha has changed, pointing once again to the relationship between temporality, life events and research. This article was first drafted when my mother was still alive and participating in boliyan and giddha and I was trying to amass an archive in order to broaden my repertoire to be practised with her. Since her death, I have had to recalibrate my attachment to building a performative digital resource of giddha and song. I 
now carry the project with a very different investment, my relationship is more abstract, distant, generalised and less immediate. Attending to knowledge gaps in a recorded archive of scripts, audio and filmic recordings will enable us to create touch points for connecting through the dots and damages of brain dementia. Dementia is increasing among South Asian populations in the United Kingdom (Turner et al., 2012). There is a clear need to improve our ways of living and caring with dementia transnationally by creatively working with what remains. In turn, we will learn to listen to what remains for those living with dementia transnationally and to not only be overwhelmed by what has been lost. Each of us, as noted by Kinnunen and Kolehmainen (2019), have biographies of touch, which carry intersubjective, familial and communal 'affective repertoires' of touch (p. 30).

\section{Concluding Remarks on Carrying as Method}

This article has mobilised the notion of carrying to understand how:

1. Carrying is entangled in inter-generational exchanges, working across archives of paper, culture, sound and bodily encounter.

2. Carrying occurs temporally with changing dimensions across a life course.

3. Carrying is networked across spaces, for instance, transnationally and diasporically.

4. Carrying is woven into methodological encounters, often as tight knots between life and research, which are grasped in partial fragments.

There are relational inter-generational connections to be made through the multisensory passing on and her-storying of artful contact zones. The importance of constituting an affective archive, as a resource of the performative practice of boliyan and giddha, lies in the communicative strength of transnational music genres for those living with dementia. The very ways in which songs live on as embodied elements of our life histories are a gift of body memory, which we can call upon, to maintain connections and enhance lives with dementia. Knowledge of specific auditory and gestural genres becomes essential for creating connections and touching care environments. The life course of what we carry as researchers is interwoven with our own biographical inspirations and junctures. The 
knots of our lives and of those around us lead us to dwell on (research) problems with an approximate element of resolve. There are some life journeys we can't run away from and in fact these entanglements offer us clues to what we can move towards.

\section{ORCID iD}

Nirmal Puwar (D) https://orcid.org/0000-0002-1652-5069

\section{Notes}

1. I would like to thank Alice Mah for drawing my attention to O'Brien's The Things They Carried during a discussion about my article.

2. Thank you to the editor Lisa Blackman and the reviewers for being receptive readers of a topic that others might pass off as 'niche' or 'ethnic'.

\section{References}

Aldridge, David (ed.) (2000) Music Therapy in Dementia Care. London: Jessica Kingsley Publishers.

Aldridge, David (2005) Case Study Designs in Music Therapy. London: Jessica Kingsley Publishers.

Berger, John and Mohr, John (2010 [1975]) A Seventh Man: Migrant Workers in Europe. London: Verso Books.

Blackman, Lisa (2010) Embodying affect: Voice-hearing, telepathy, suggestion and modelling the non-conscious. Body \& Society 16(1): 163-192.

Bourdieu, Pierre (1990) In Other Words: Essays towards a Relative Sociology. Cambridge: Polity Press.

Brah, Avtar (1996) Cartographies of Diaspora: Contesting Identities. London: Routledge.

Caldwell, Phoebe (2005) Finding You Finding Me: Using Intensive Interaction to Get in Touch with People Whose Severe Learning Disabilities Are Combined with Autistic Spectrum Disorder. London: Jessica Kingsley Publisher.

Caldwell, Phoebe and Horwood, Jane (2007) From Isolation to Intimacy: Making Friends without Words. London: Jessica Kingsley Publishers. 
Cho, Grace M (2008) Haunting the Korean Diaspora: Shame, Secrecy, and the Forgotten War. Minneapolis, MN: University of Minnesota Press.

Clark, Camilla N and Warren, John D (2015) Music, memory and mechanisms in Alzheimer's disease. Brain 138(8): 2122-2125.

Commission on Dementia and Music (2018) What Would Life Be Without a Song or Dance, What Are We? London: International Longevity Centre (UK) and Utley Foundation.

Connerton, Paul (1989) How Societies Remember. Cambridge: Cambridge University Press.

Cvetkovich, Ann (2003) An Archive of Feelings: Trauma, Sexuality, and Lesbian Public Cultures. Durham, NC: Duke University Press.

Cvetkovich, Ann and Carland, Tammy R (2013) Sharing an archive of feelings: A conversation. Art Journal 72(2): 70-77.

Daughtry, Martin (2017) Acoustic palimpsests. In: Kapchan, Deborah (ed.) Theorizing Sound Writing. Middletown, CT: Wesleyan University Press, pp. 46-85.

David, Ann (2015) Embodied cultural memories of the Punjab: Giddha dance and song in migrant London spaces. Traditiones 44(2): 149-171.

DeCerteau, Michel, Giard, Luce and Mayol, Pierre (1998) The Practice of Everyday Life (Vol. 2), Tomasik, Timothy J (Trans.). Minneapolis, MN: University of Minnesota Press.

Ellis, Maggie P and Astell, Arlene J (2004) The urge to communicate in severe dementia. Brain and Language 91(1): 51-52.

Ellis, Maggie P and Astell, Arlene J (2008) A case study of adaptive interaction: A new approach to communicating with people with advanced dementia. In: Zeedyk, Mary Suzanne (ed.) Promoting Social Interaction for Individuals with Communicative Impairments: Making Contact. London: Jessica Kingsley Publishers.

Ellis, Maggie P and Astell, Arlene J (2011) Adaptive interaction: A new approach to communication. Journal of Dementia Care 19(3): 24-26.

Ferzacca, Steve (2004) Lived food and judgments of taste at a time of disease. Medical Anthropology 23: 41-67.

Fraser, Nancy (2007) Transnationalizing the public sphere: On the legitimacy and efficacy of public opinion in a post-Westphalian world. Theory, Culture \& Society 24(4): 7-30. 
Gunaratnam, Yasmin (2012) Learning to be affected: Social suffering and total pain at life's borders. The Sociological Review 60: $108-123$.

Gunaratnam, Yasmin (2013) Death and the Migrant: Bodies, Borders and Care. London: Bloomsbury.

Hall, Stuart (1999) Whose heritage? Un-settling 'the heritage', reimagining the post-nation. Third Text 13(49): 3-13.

Haraway, Donna (1994) A game of cat's cradle: Science studies, feminist theory, cultural studies. Configurations 2(1): 59-71.

Haraway, Donna (2008) When Species Meet. Minneapolis, MN: University of Minnesota Press.

Hartman, Saidiya (2008) Venus in two acts. Small Axe 12(2): 1-14. Hartman, Saidiya (2019) Wayward Lives, Beautiful Experiments: Intimate Histories of Social Upheaval. New York, NY: W. W. Norton \& Company.

Hayden, Jane S (2007) Some enchanted evening ... : Like magic, a familiar song conjures up memories of a happier time. Nursing 37(10): 42-43.

Kinnunen, Taina and Kolehmainen, Marjo (2019) Touch and affect: Analysing the archive of touch biographies. Body \& Society 25(1): 29-56.

Le Guin, Ursula K (1989) The carrier bag theory of fiction. In: Le Guin, Ursula K (ed.) Dancing at the Edge of the World: Thoughts on Words, Women and Places. New York, NY: Grove Press, pp. 165-167.

Lee, Sandra Soo-Jin (2000) Dys-appearing tongues and bodily memories: The aging of first-generation resident Koreans in Japan. Ethos 28(2): 198-223.

Lepecki, Andre (2010) The body as archive: Will to re-enact and the afterlives of dances. The Dance Research Journal 42(2): 28-48.

Maguire, Linda, E, Wanschura, Patricia B, Battaglia, Margorie M, et al. (2014) Participation in active singing over a 4-month period leads to cognitive improvements in a group of patients with dementia. Journal of the American Geriatrics Society 63(4): 815-816.

Mani, Lata (1992) Cultural theory, colonial texts: Reading eyewitness accounts of widow burning. In: Grossberg, Lawrence, Nelson, Cary, and Treicher, Paula (eds) Cultural Studies. Abingdon: Routledge, pp. 392-405. 
Mani, Lata (1998) Contentious Traditions: The Debate on Sati in Colonial India. Berkeley, CA: University of California Press.

Marres, Noortje (2014) Material Participation: Technology, the Environment and Everyday Publics. Basingstoke: Palgrave Macmillan.

Marres, Noortje, Lezaun, Javier and Tironi, Manuel (2016) Experiments in participation. In: Miller, Clark A, Smith-Doerr, Laurel, Felt, Ulrike, and Fouche, Rayvon (eds) The Handbook of Science and Technology Studies. Cambridge, MA: MIT Press, pp. 195-222.

Motamedi Fraser, Mariam (2015) Word: Beyond Language, Beyond Image. London and New York: Rowman \& Littlefield.

Mountz, Alison, Bonds, Anne, Mansfield, Becky, et al. (2015) For a slow scholarship: A feminist politics of resistance through collective action in the neoliberal university. ACME: An International Journal for Critical Geographies 14(4): 1235-1259.

Narvaez, Rafael F (2006) Embodiment, collective memory and time. Body \& Society 12(3): 51-73.

O'Brien, Tim (1990) The Things They Carried. Boston, MA: Houghton Mifflin Harcourt.

Omar, Rohani, Hailstone, Julia C, Warren, Jane E, et al. (2010) The cognitive organization of music knowledge: A clinical analysis. Brain 133: 1200-1213.

Parmar, Prabhjot and Puwar, Nirmal (2019) Striking a chord: Dementia and song. Performance Research 24(1): 25-34.

Portelli, Alessandro (1997) The Battle of Valle Giulia: Oral History and the Art of Dialogue. Madison, WI: University of Wisconsin Press.

Purewal, Navtej and Kalra, Virinder (2010) Women's 'popular' practices as critique: Vernacular religion in Indian and Pakistani Punjab. Women's Studies International Forum 33: 383-389.

Puwar, Nirmal (2007) Social cinema scenes. Space and Culture 10(2): 253-270.

Puwar, Nirmal and Sharma, Sanjay (2011) Introduction: War cries. Senses and Society 6(3): 261-266.

Rajan, Rajeswari Sunder (1993) Real and Imagined Women: Gender, Culture and Postcolonialism. London: Routledge.

Sonntag, Jan (2016) Atmosphere - An aesthetic concept in music therapy with dementia. Nordic Journal of Music Therapy 25(3): 216-228. 
Spivak, Gayatri Chakravorty (1988) Can the subaltern speak? In: Nelson, Cary and Grossberg, Lawrence (eds) Marxism and the Interpretation of Culture. New York, NY: Macmillan, pp. 276-278.

Stalpaert, Christel (2011) Re-enacting modernity: Fabian Barba's $A$ Mary Wigman Dance Evening. Dance Research Journal 43(1): 90-95.

Steedman, Carolyn (1986) Landscape for a Good Woman. London: Virago Press.

Steedman, Carolyn (2000) The watercress seller. In: Spargo, Tamsin (ed.) Reading the Past: Literature and History. Basingstoke: Palgrave, pp. 18-25.

Steedman, Carolyn (2001) Dust: The Archive and Cultural History. Manchester: Manchester University Press.

Stoler, Ann (2010) Along the Archival Grain. Princeton, NJ: Princeton University Press.

Strathern, Marilyn (2004) Partial Connections. Toronto: AltaMira Press.

Taylor, Diana (2003) The Archive and the Repertoire. Durham, NC: Duke University Press.

Turner, Daniel, Salway, Sarah, Chowbey, Punita, et al. (2012) Mini Case Study Book: Real World Examples of Using Evidence to Improve Health Services for Minority Ethnic People. Available at: http://clahrcsy.nihr.ac.uk/images/health\%20inequalities/ resources/EEiC_mini_case_study_book.pdf (accessed 20 September 2019).

Waller, Diane and Beeharee, Kamal (2002) Changing the context of care: Opening up the system. In: Waller, Diane, (ed.) Arts Therapies and Progressive Illness: Nameless Dread. Hove: Routledge, pp. 138-144.

\section{Filmography}

Aaj Kaal (1990), produced by participants at the Milap Asian Day Centre. Organised by Avtar Brah, Jasbir Panesar and Vipin Kumar. Extra-Mural Studies, Birkbeck College, University of London. Available at: http://www.darkmatter101.org/site/2012/ 04/03/aaj-kaal-yesterday-today-tomorrow-video/. 
Alive Inside (2014), Dir. Michael Rossato-Bennett. Produced by Projector Media.

Unravelling (2008), Dir. Kuldip Powar. Produced by Goldsmiths, University of London. Funded by AHRC.

Nirmal Puwar is a Reader at Goldsmiths, University of London. She is the author of Space Invaders: Race, Gender and Bodies Out of Place (2004) and co-editor of 18 collections including Live Methods, Intimacy in Research, Post-colonial Bourdieu, Fashion and Orientalism and South Asian Women in the Diaspora. She is Co-convenor of MA Gender, Media and Culture. She has collaboratively worked on a number of projects involved with inventive and public methods, including memorials for the AHRC 'Noise of the Past' project. She is currently writing a walking memoir of urban history. 